\title{
Architectural Design Confluence: When Pencil Met Computer in Conceptual Strategies of Design
}

\author{
Kyari Muhammadu Habibullah ${ }^{1} \quad$ Muhammad Umar Jekadafari $^{2} \quad$ Badara B. Bakoji ${ }^{2}$ \\ Kawuwa Abubakar Sarkile ${ }^{2} \quad$ Hamidu Bushira $^{3}$ \\ 1.Faculty of Design and Architecture, Department of Architecture, Universiti Putra Malaysia \\ 2.Department of Architecture, Abubakar Tafawa Balewa University, Bauchi, Nigeria \\ 3.Department of Library Sciences, Abubakar Tafawa Balewa University, Bauchi, Nigeria
}

\begin{abstract}
Drawing and sketches are closely linked to the artist and are the best way to create a graphic image in the mind of the designer at the level of conceptualization of the design process. However, the use of the device has begun to be implemented in the early stages of the Architecture. In the opinion of the authors, the UPM Bachelor of Architecture students can be divided into two groups: one using 2D and 3D AutoCAD as the only means of drawing and modeling, weekly workshops and presentations, and one using traditional drawing and modeling. The question here is that while students use computers as a drawing medium in the conceptual design process, can different design results be achieved when compared to the use of pencils or other media? In addition, this paper also addresses the importance of using computers for student learning and studio culture in the early stages of design process.
\end{abstract}

Keywords: AutoCAD 3D, Computer, Graphics, Pencil Design Process, Studio Culture

DOI: $10.7176 / \mathrm{JEES} / 10-7-08$

Publication date:July $31^{\text {st }} 2020$

\subsection{INTRODUCTION}

Analysis, concept generation, preliminary design, and detail design are several stages involved in design process. Concept generation stages belong to early part of design process and many design educators agreed with the importance of sketching drawing and model-making in the stage of concept generation. Sketch and drawing, are much concerned with visual thinking. Ching Juroszek, (2013) emphasized that pencil sketching and drawing remain a cognitive process that involves perspective seeing and visual thinking which associated with the preliminary design phase. They clarify the relationship between drawing and thinking, and point out that drawing is the best and the fastest way to visualize the thinking of a designer.

Kasprisin and Pettinari (2013) pointed out that designers view drawing as a way of speaking, a flexible language that enables the designer to present an idea or a policy and to organize the idea. With the advent of industrialization, a computer has become the designers' standard tool in both academia and the profession. However, most of the software programs available for the designers such as Photoshop, AutoCAD, 3D Studio, and Maya etc. are devised for either documenting well-conceived ideas precisely or for special effect and animation (Paranandi, 2012). In other words, they are mainly restricted within the latter stages of design process and not really geared towards Architectural problem solving. But in recent years, the use of computer- aided design (CADD) in the forepart of design process, which is the stage of concept generation, has started to generate. According to Phiri (2012), intuitive conceptual-design using computer software packages with outputs of freeform sketches and 2D illustrations are now being introduced. (Laiserin and Linn, 2015) also agreed that CAD addons, such as Live Styles for ArchiCAD or Squiqqle for AutoCAD can make 2D CAD line work looks like hand drawn.

The authors observed that the undergraduate of the department of Architecture of the Abubakar Tafawa Balewa University seemed to be in two distinctive groups: one used 2D and 3D AutoCAD as the tools used for drawing and modeling, weekly tutorials and reviews, and another used conventional tools of drawing and model making. The major question of this study is that while students use computers as the sketching media in the conceptual stage of design process, will there be any improvement in the student's design outcomes compared to using pencil or any other conventional media? In other words, this paper discusses the effectiveness of the computer as the primary design and development method in formulating design principles.

\subsection{THE ROLE OF SKETCHING AND DRAWING WITHIN DESIGN PROCESS}

Somewhat interchangeably, designers use the words "diagrams," "sketch," and "schematic drawing." Here, the authors used the terms drawing and drawing to refer to the designers' sketches during the early design process as shown in figure 1. 


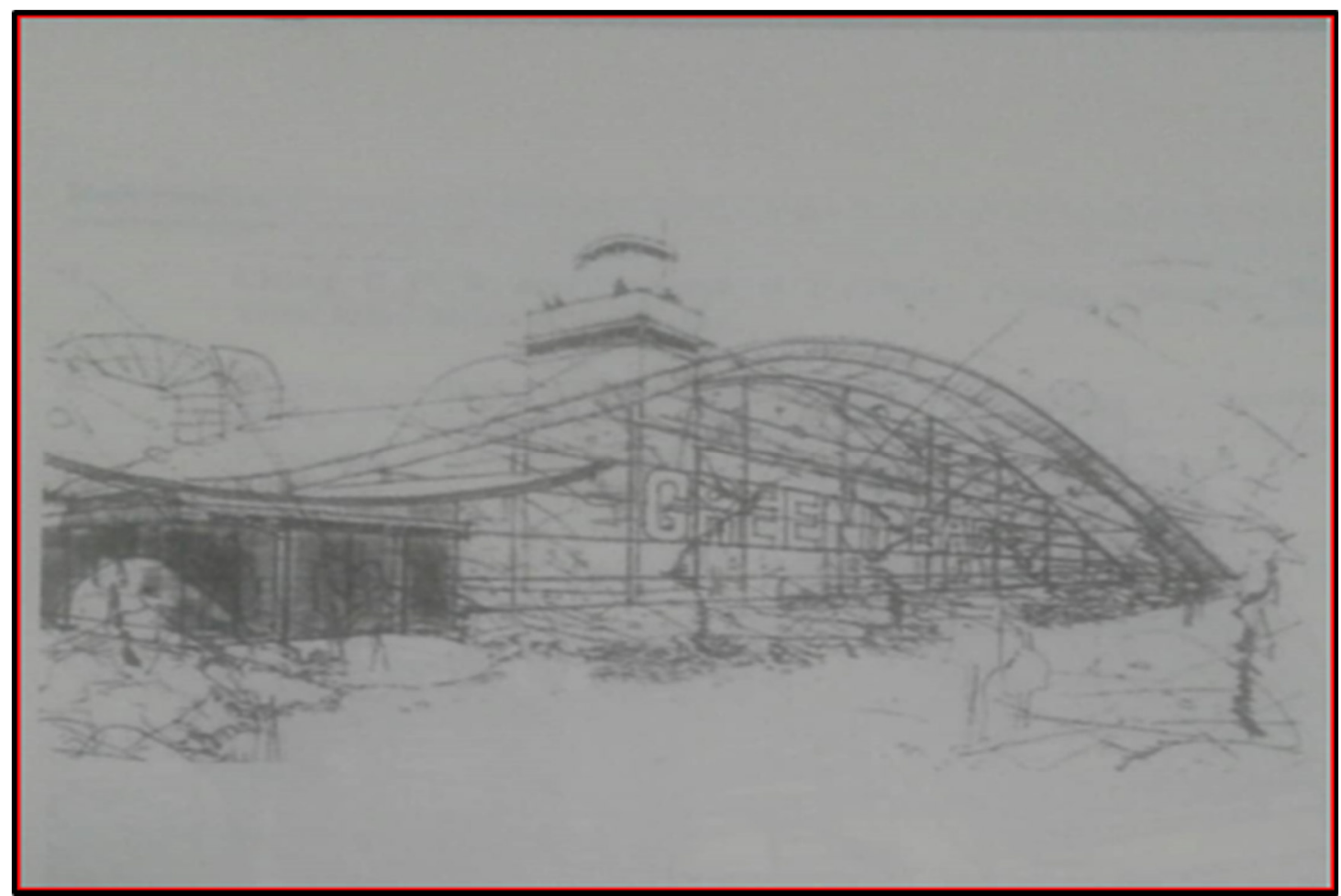

Figure 1: Schematic Drawing

Learning how to draw by hand has long been a critical skill for the Architects. It helps develop the capacity to conceive spaces and express what is imaginable. In drawing, neuro-muscular training is needed for the brain, hand, and eye from Laiserin and Linn (2015). In graphic thinking, Laseau (2013) argues that conceptual drawings are intended to raise concerns and provoke further design decisions. Lawson (2014) describes that designers "find it hard to think without a pencil in their mind". He further argues that designers are needed to draw in order to think, and conclude that a failure to draw may indicate a gap in thought.

The greatest challenge for architectural students is the development of the visualization skills needed to facilitate design (conceptualization). The methods of visualization has been drawing and model making. While these are important, they require the students to be reasonably skilled before they can represent their ideas. The relationship between the medium of representation and design is such that unless a student can 'visualize' their design conception they cannot develop or improve the design. So if they cannot draw, they cannot see, and cannot design. Therefore, if we assume that first year architectural students have not yet learn to draw, we also assume that their design potential will be held back until they can 'see' Hutson, (2015).

In this process of searching for design concept, designers need to think freely. Much is implied in the sketch which is usually used for conceptualizing and visualizing. At this stage of design process, it is necessary to be able to make sketches quickly since they represent alternative design ideas for an imagined conception Yee, (2013). So does it mean sketching remains the preferred tool than computer? Well, maybe yes.

An obvious reason is that at the start of the programmes, the students' initial exploration of ideas is hampered by their lack of proficiency with the computer. Another reason is that a powerful modeling program is often more of a barrier than a help in the process of trying out ideas. Computers require precision and coordinates, and an inexperienced designer using a computer is tempered to incorporate an inappropriate level of detail to what should be a schematic study of major concepts (Pressman, 2012).In addition, it takes more time to use the mouse to draw free hand and demands more control than the pencil and paper. It does not have range of thickness and intensity and therefore cannot express the weight and emphasis intended for the aspect of the ideas that have been drawn. This lack of fluidity in the initial stages hinders the range, speed, and flow of drawing as a design tool, when designers need freedom to explore ideas through drawing.

Isn't it rather absurd to use a computer and printer in an attempt to duplicate the look of any conventional medium created on paper or canvas? If what is needed is a pencil drawing, why not execute the drawing in pencil? Of course, whether the medium is real pencil or digital pencil, the task is different if the person has not learned to draw. Dorsey, and McMillan (1997); as cited by Paranandi, (2016) mentioned that current computer graphics systems lack the accommodation for ambiguity and the elegance of pencil sketches on butter paper to record the design process and compare multiple solutions simultaneously. See freehand pencil sketches in figure 2. 


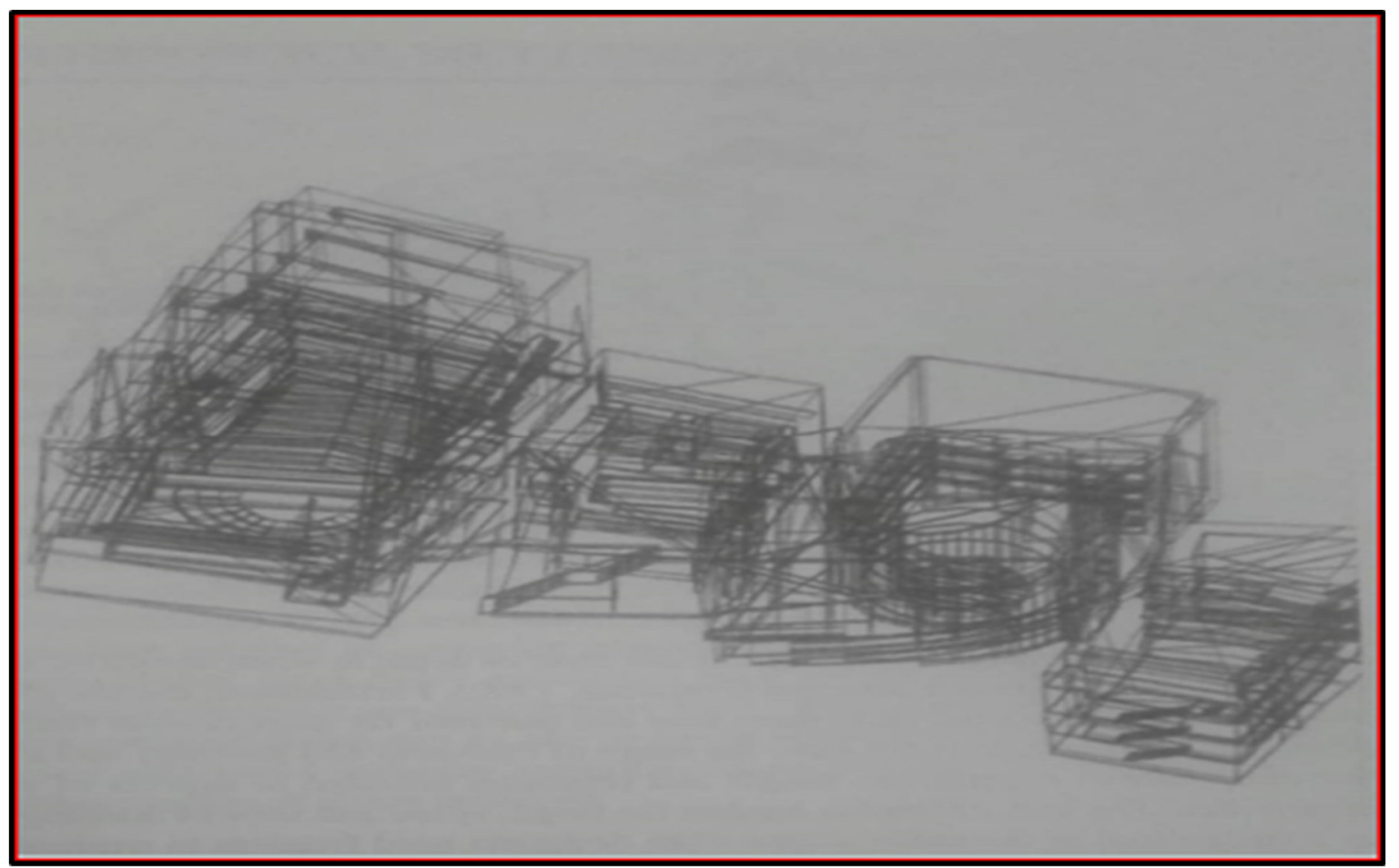

Figure 2: Freehand Pencil Sketch Drawing

Regardless of these limitations of computer in early stage of design, there now exists a considerable number of designers/architects such as Frank O. Gehrry, Greg Lynn, Rem Koolhaas and Peter Eisenman who used computer from the earliest stages of design and demonstrates innovative use of computer modeling in their architecture. Laiserin and Linn (2015) opined that any Architect working directly in 3D computer models can explore hundreds of perspectives or analyze digitally animated paths. However, it must be pointed out that Gehrry, Lynn Koolhaas and Eisenman schooled before computers and bring decades of hands-on experience to the digital world.

The above mentioned are experienced designers and it is quite impossible for undergraduate architecture students to follow their design methods. For students, both media can be used simultaneously in concept generation stage or during the course of massing/parti study. A quick 3D AutoCAD model can be developed for the variations and used as a base for further refinement with spontaneous pencil sketches as shown in figure 3 below.

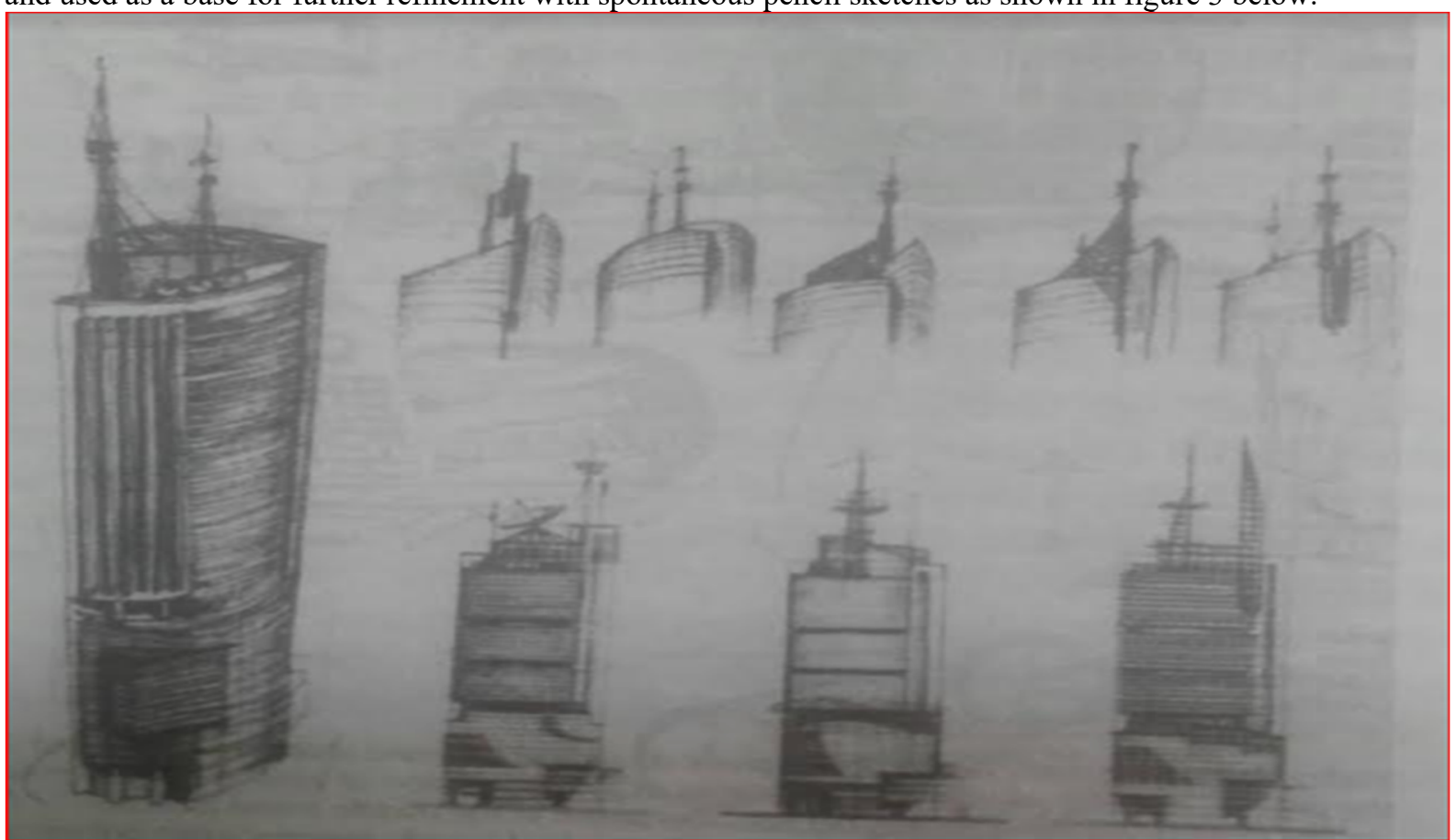

Figure 3: 3D AutoCAD Sketch 


\subsection{IMPACT OF COMPUTER IN STUDENTS' LEARNING AND STUDIO CULTURE}

Through the authors observation as design educators and computer literate, there are some consequences of making computer as a design tool for students as early as the conceptual stages of the design to their learning and studio culture.

Firstly, there is a group of undergraduate students who spent a large part of the assigned project time on learning to master the CAD rather than spending time on designing. Consequently, this group of students did not examine the structural and constructional aspect of the design as much as the groups who were working more conventionally.

This makes it an imbalanced comparison with those who were using only conventional tools as they were able to dedicate all their time to designing. These extra contributions of structural and construction studies by students who used conventional tools are considered as an additional value to the students' learning capacity and design outcome. Nevertheless, it is quite logic that those students who use computers have the means to explore 3Dcomposition when conventional methods of drawing would not have been adequate. Furthermore, they produced more 3D views than those who used conventional tools.

Secondly, there is less idea-interaction between students as one work before the screen for the whole day, coupled with the need to work at home where the workstation is located. Consequently, the studio, a place where idea-interaction among students should take place becomes progressively deserted.

Thirdly, the students' observation on graphic presentation, especially in digital form, tends to create a more formal relationship between the tutors and the students. When one works with the computer, even weekly progress discussions will tend to be in a package presentation form. The computer screen becomes the media between tutorstudent communications, very much like the business presentations between associates. The learning environment is thus becoming isolated.

\subsection{CONCLUSION}

It seems that computer skills have become essential to young Architects seeking jobs in the current markets, but it does not mean that Architecture students are allowed to overwhelm themselves with computer-aided design (CADD) at the expense of drawing skills. The intention of this paper is not to conclude that one is better than the other, but using them in concert enriched the design process. Experience will make it clear which media is best for which design problem. For design educator's point of view, the rush to computerized education may occur at the expense of creativity, the ability to visualize and think spatially, and knowledge gained through learning traditional drafting. The traditional skills of drawing will not be replaced by computer, but rather they will develop in parallel; with a better understanding of the 3D environment within which Architecture occurs.

\section{REFERENCES}

Ching, F.D.K. and Juroszek, S.P. (2013), Design Drawing. New York. John-Willey and sons, Inc.

Hudson, Andrew. (2015), The Medium is the Message. Proceedings of the $5^{\text {th }}$ Conference on Computer Aided Architectural Design Research in Asia (CAADRIA), Singapore, May, pp191-200.

Kasprisin, R. and Pettinari, J. (2013), Visual Thinking for Architects and Designers: Visualizing Context in Design. New York: Van Nostrand Reinhold.

Laiserin, J. and Linn, C. (2015), Challenge for the Digital Generation, Architectural Records; December 2015 Edition. New York

Laseau, Paul. (2013), Graphic Thinking for Architects and Designers, $3^{\text {rd }}$ Ed. New York: Van Nostrand Reinhold. Lawson, Bryan. (2014), Design in Mind. London: Butterworth-Heinemann Ltd.

Paranandi, Murali. (2016): An Inquiry into Computers in Design. Proceedings of the $7^{\text {th }}$ Conference on Computer Aided Architectural Design Research in Asia (CAADRIA), Malaysia, April, Pp329-324.

Phiri, Michael. (2012), Information Technology in Construction Design, London: Thomas Telford Publishing.

Pressman, Andy. (2012), Architecture 101: A Guide to the Design Studio. New York: Wiley and Sons Inc.

Yee, Rendow. (2013), Architectural Drawing: A Visual Compendium of Types and Methods.

New York: Wiley and Sons Inc. 